Sf存 Universidad

辛: de Alcalá

\title{
BIBLIOTECA
}

Document downloaded from the institutional repository of the University of Alcala: http://dspace.uah.es/dspace/

This is a postprint version of the following published document:

Bullock, J.M. et al., 2011. Restoration of ecosystem services and biodiversity: conflicts and opportunities. Trends in Ecology \& Evolution, 26(10), pp.541-549.

Available at https://doi.org/10.1016/i.tree.2011.06.011

(C) 2011 Elsevie
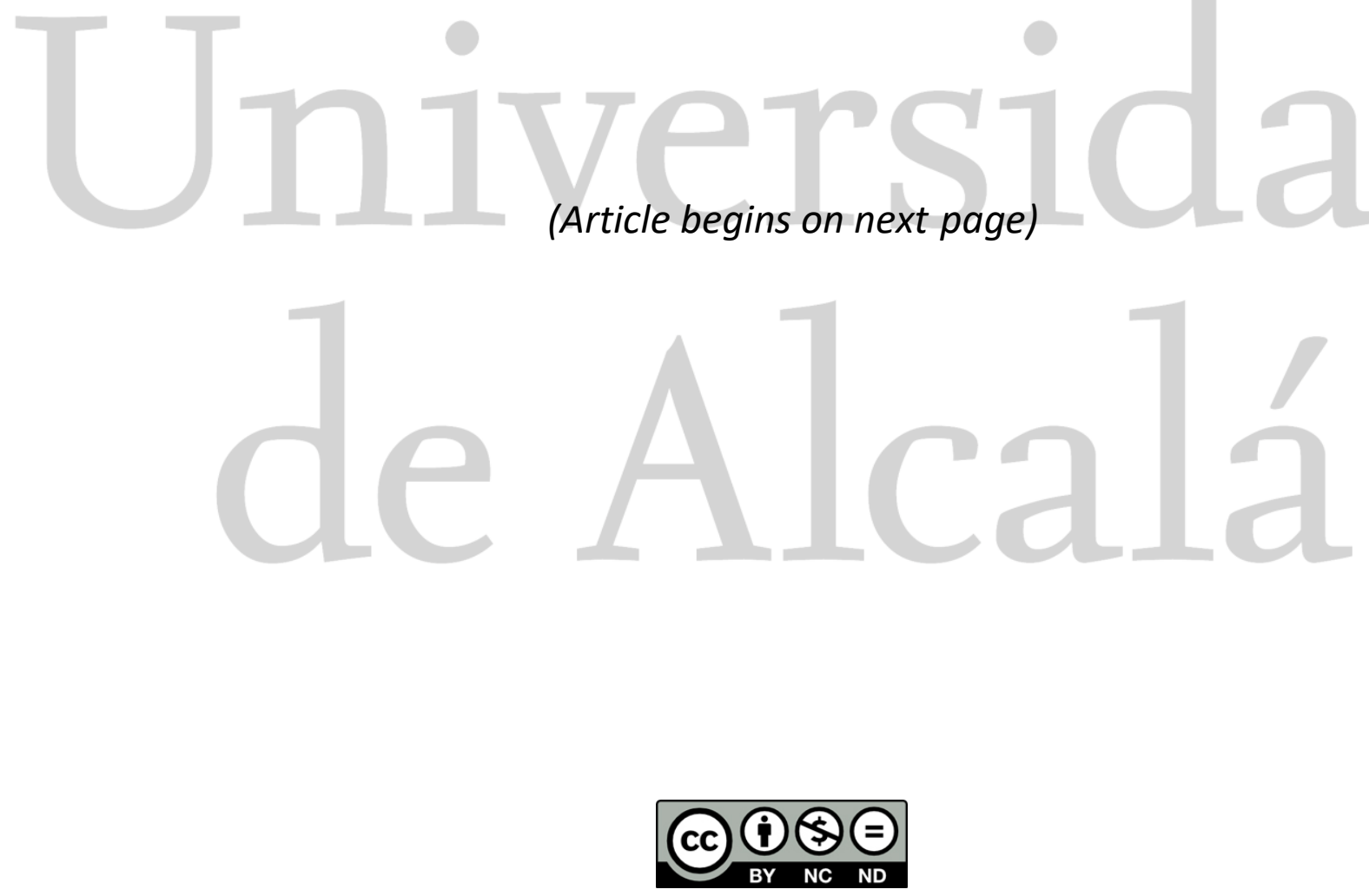

This work is licensed under a

Creative Commons Attribution-NonCommercial-NoDerivatives

4.0 International License. 


\section{Restoration of ecosystem services and biodiversity: conflicts and}

\section{opportunities}

James M. Bullock ${ }^{1}$, James Aronson ${ }^{2,3}$, Adrian C. Newton ${ }^{4}$, Richard F. Pywell ${ }^{1}$ and Jose M. Rey-Benayas ${ }^{5}$

(after the $1^{\text {st }}$ author, the remaining authors are listed alphabetically to emphasise their equal contributions)

${ }^{1}$ Centre for Ecology and Hydrology, Maclean Building, Benson Lane, Crowmarsh Gifford, Wallingford, Oxfordshire, OX10 8BB, UK

${ }^{2}$ CNRS, Centre d'Ecologie Fonctionnelle et Evolutive, UMR 5175, F-34033 Montpellier, France

${ }^{3}$ Missouri Botanical Garden, St Louis, Missouri, USA

${ }^{4}$ School of Conservation Sciences, Bournemouth University, Talbot Campus, Poole, Dorset, BH12 5BB, UK

${ }^{5}$ Ecology Department, Edificio de Ciencias, Alcala University, E-28871 Alcalá de Henares, Spain

Corresponding author: Bullock, J.M. (jmbul@ceh.ac.uk) 


\begin{abstract}
Ecological restoration is becoming regarded as a major strategy for increasing provision of ecosystem services as well as reversing biodiversity losses. We show that restoration projects can be effective in enhancing both, but conflicts can arise, especially if single services are targeted in isolation. Furthermore, recovery of biodiversity and services can be slow and incomplete. Despite this uncertainty, new methods of ecosystem service valuation are suggesting that the economic benefits of restoration can outweigh costs. Payment for Ecosystem Service schemes could therefore provide incentives for restoration, but require development to ensure biodiversity and multiple services are enhanced and the needs of different stakeholders are met. Such approaches must be implemented widely if new global restoration targets are to be achieved.
\end{abstract}

\title{
Environmental degradation and the role of restoration
}

Human exploitation and conversion of the world's ecosystems is causing widespread biodiversity loss and declines in ecosystem condition, leading to reduced provision of ecosystem services [1-3]. International initiatives to address these impacts, including the Convention on Biological Diversity (CBD), the Millennium Development Goals, and the Intergovernmental Science-Policy Platform on Biodiversity and Ecosystem Services, explicitly link the conservation of biodiversity with the provision of ecosystem services to support sustainable development and poverty reduction [4]. As ecological restoration can potentially contribute to improvement of human livelihoods, as well as enhancing biodiversity, it is assuming an increasingly central role in global environmental policy [2,5-7]. This is illustrated by the 2020 Headline Targets developed recently by the CBD (see: 
http://www.cbd.int/decision/cop/?id=12268 ), which aim for the restoration of ecosystems that provide essential services (Target 14), and enhancement of the contribution of biodiversity to carbon stocks through restoration of at least $15 \%$ of degraded ecosystems (Target 15). Similarly the European Union aims to cease biodiversity loss and degradation of ecosystem services by 2020, and to restore them "so far as feasible" (see: http://www.euun.europa.eu/articles/en/article_9571_en.htm).

While the science and practice of ecological restoration have developed rapidly, the emerging policy focus on ecosystem services represents a significant shift in the objectives of restoration. This may give rise to both conflicts and opportunities. Some commentators have expressed fears that a focus on ecosystem services may be at the expense of biodiversity conservation $[8,9]$, while others have suggested that markets for ecosystem services may provide funding for conservation activities [10]. Here we explore in detail the implications of this policy shift by examining whether ecological restoration could be effective in reversing the decline of ecosystem services along with biodiversity. Specifically, we ask the following questions. Can restoration achieve the desired increases in both biodiversity and services? Will a focus on ecosystem services allow restoration costs to be offset by their potential economic benefits? Finally, will the economic value of ecosystem services provide a mechanism by which global restoration targets might be achieved in practice?

\section{Restoration of ecosystem services and biodiversity}

The evidence for biodiversity effects on ecosystem services 
The Millennium Ecosystem Assessment [12] and many subsequent publications [14] suggest that biodiversity and provision of ecosystem services are positively related, with the implication that management to enhance one should increase the other. However, analysis of empirical evidence shows that this relationship is complex and not always positive $[15,16]$. Species richness has been linked positively to a number of ecosystem processes, leading to enhanced provision of ecosystem services $[17,18]$. On this basis, actions that increase species richness should also benefit services. However, this cannot be considered as a general rule. Most studies of the relationship between biodiversity and ecosystem function consider a limited number of ecological processes that relate almost exclusively to resource utilization [19]. Furthermore, the increase in ecosystem processes often reaches a plateau at moderate species numbers [20]. Species identity effects add an extra level of complexity, especially as the rare species frequently targeted by conservation efforts often have minor effects on ecosystem processes, whilst commoner species can have a dominant role [20,21]. Ecosystem diversity effects on services are even less clear. Work is only beginning to examine how the variation of ecosystems across landscapes affects service delivery [22]. Variation among ecosystems in processes and service provision is not necessarily coincident with differences in either species richness or measures of conservation value. Indeed, mapping of ecosystem services and biodiversity measures at a variety of scales has repeatedly indicated a lack of spatial concordance [23,24].

\section{Impacts of restoration on biodiversity and ecosystem services}

The findings summarised above suggest that restoration projects focussing on the enhancement of biodiversity will not necessarily increase provision of ecosystem services. A meta-analysis of 89 restoration projects indicated correlated increases in 
biodiversity and ecosystem services in restored compared to degraded systems [25], but this is not necessarily evidence for a causal link, and more likely reflects common responses to restoration actions. Indeed, rather than treating biodiversity and ecosystem services as a cause-effect relationship, we suggest that restoration projects should be designed with consideration of how biodiversity and ecosystem services will respond to possible management actions and whether these responses will coincide or conflict (Fig. 1).

Some restoration initiatives illustrate how benefits to both biodiversity and provision of ecosystem services can be achieved in practice. For example, the restoration of native jarrah forest on bauxite mines in Western Australia enhanced plant and vertebrate diversity as well as carbon sequestration and water storage [29]. Restoration management of the Arkansas River, by the cessation of heavy metal inputs, increased water quality and allowed recovery of fish and invertebrates [30]. Re-instatement of meanders in German rivers both decreased flooding risk and increased the diversity of the invertebrate fauna [31].

However, other examples indicate that restoration will not inevitably enhance both biodiversity and services. Under China’s Grain to Green Project (GTGP), which aims to restore services and biodiversity [15], activities include planting non-native trees on agricultural land to decrease soil erosion. This has led to decreased native vegetation cover and increased water use, suggesting negative impacts on biodiversity and water availability in arid areas [28]. The use of non-native species to restore specific services can diminish native species and instigate damaging invasions [32,33]. Restored species-rich grasslands often produce less forage than their fertilised 
agricultural predecessors [18]. Restoration of boreal forest structure by felling to encourage regeneration of broad-leaved trees also provides habitat for bark beetles, which reduce timber production in adjacent forestry [34]. Finally, restoration of oyster populations to reduce eutrophication in estuaries has been projected to have negative effects on pelagic consumer taxa [35].

\section{Limitations on the restoration of biodiversity and ecosystem services}

It has long been recognised that the effectiveness of restoration projects must be evaluated against a reference [36]. In practice the reference has often been the attributes of an un-degraded ecosystem [25,37-39], which can either be the presumed historic state or an extant natural or semi-natural ecosystem. Although recovery towards the reference varies greatly among restoration projects (Box 1), some generalisations are available. A meta-analysis which included a wide range of biomes found that restoration was only partially successful in achieving reference conditions, as restored systems had median measures of $86 \%$ of the biodiversity and $80 \%$ of the services associated with reference ecosystems [25]. Similarly, a study of restored lands across the United States showed that these provided $31 \%$ to $93 \%$ of the services supplied by the reference prairie, forest, wetland, or desert ecosystems within a decade after restoration [38]. Therefore, while individual restoration projects can be highly successful [29,50], multi-site evaluations indicate a widespread failure to fully restore the biodiversity or ecosystem services to those of reference ecosystems $[40,41,48,53]$.

The policy shift towards restoration of ecosystem services might lead towards selection of references based on provision of a single service. An increase in the 
provisioning of a specific ecosystem service is the clear aim in some restorations, including examples focusing on coastal protection [33], soil stabilisation [54] or aesthetic appeal [55]. It has been suggested that "novel ecosystems" might be created that do not resemble taxonomically any historical ecosystem, but deliver required services [56]. These aims may be more easily achievable than restoring the characteristics of reference ecosystems, but they may lead to conflicts with biodiversity conservation [54], and may be better considered as rehabilitation rather than restoration [11].

\section{Do the benefits from ecosystem restoration outweigh the costs?}

Although the reference may not be achieved, restoration tends to increase ecosystem services compared to the degraded systems [25]. These ecosystem services can be considered in terms of benefits against which restoration costs can be set. Unfortunately, cost-benefit analyses of restoration projects are scarce; records of restoration costs are rare in the scientific literature, and the benefits to society have rarely been examined in detail [57]. Approaches to costing are various and hard to compare. For example, a mangrove restoration project in Thailand was estimated to cost US\$8240 ha ${ }^{-1}$ in the first year followed by annual maintenance costs of $\$ 118 \mathrm{ha}^{-1}$ [58]. By contrast, reported annual costs for restoring mangroves in the Gulf of Mexico were nearly double that of the Thailand project [59].

The Economics of Ecosystems and Biodiversity project recently reviewed over 20,000 restoration case studies, yet only 96 studies provided meaningful cost data [60]. The breadth and quality of information varies among studies. Some provide only aggregate costs, while others only report capital or labour costs. Some restoration 
activities are conducted for research purposes and no accounting is done.

Furthermore, some project accountants consider wages paid to labourers as costs, whereas in others (e.g. the South African Government's Working for Water programs, [61]) they are treated as costs and benefits. However, some tentative conclusions can be drawn [60]. Project costs vary with ecosystem type, ranging between several hundreds to thousands of US\$ha ${ }^{-1}$ (grasslands, rangelands and forests) to several tens of thousands (inland waters), or millions of $\$ \mathrm{ha}^{-1}$ for coral reefs. Costs vary according to timescales for success and the methods used, and these vary as a function of ecosystem type, the aim of the restoration, and the degree of degradation.

\section{Accounting for restoration benefits to people}

Analysis of the benefits of restoration to people is in its infancy, but recent developments in valuing ecosystem services provide a basis for estimating economic benefits [62]. Many goods and services can be given monetary value using a range of economic approaches [63]. A critical aspect of monetary analysis is the discount rates used to assess the present value of future benefits. Different rates can produce highly contrasting economic outcomes [64] and there is no consensus as to what rate, if any, should be applied to restoration projects [65]. In addition, some services cannot be monetized, such as many cultural services which reflect societal values. In such cases 'non-monetizing' approaches have been suggested, which involve analysing choices and preferences of stakeholders [63]. A focus on restoration for ecosystem services will require increasing emphasis on incorporation of such stakeholder values in decision-making. 
Once valued, the economic benefits of restoration can be compared against costs (Box 2). One approach is to calculate return-on-investment [68], which requires estimates of the total economic value of short- and long-term benefits. As ecosystem benefits are often unknown or imprecise, the measure is often uncertain. When applied to restoration, this uncertainty is even greater since returns will come in the form of a range of different values, potentially over long periods of time. A useful initial step is to compare actual and potential direct-use values (e.g. [69]). However, indirect consumption values for ecosystem services ultimately need to be factored in, as well as option, existence, and bequest values, which capture the possible future use of services.

Despite these uncertainties, and although very few analyses of the cost-effectiveness of ecological restoration have been undertaken to date, evidence suggests that restoration can be cost effective, at least when relatively low-cost methods are employed (Box 2).

\section{Paying for restoration through ecosystem services}

\section{Funding restoration through PES schemes}

One of the principal challenges in a restoration project is to cover the costs. Conventionally, restoration has been considered simply as a cost to be paid, for example through government funding [40], by companies restoring ecosystems degraded by their activities [29], or through biobanking and biodiversity offsetting initiatives [70]. An ecosystem service perspective emphasises the social and economic benefits of restoration and implies a role for Payment for Ecosystem Services (PES) schemes, which are designed to compensate individuals or communities for actions 
that maintain or increase the provision of services $[71,72]$. In recent years many hundreds of PES schemes have been established worldwide to finance environmental management, including restoration [72]. As for any market, the development of a PES system requires that there be willing buyers and sellers of a service, at an agreed-upon price which is facilitated by a functioning institutional arrangement [73]. Since many returns from restoration will be realised only in the long term and in the realm of broader public interests, government investment is often needed [74]. For some services the relationship between buyer and seller is relatively direct; e.g. city dwellers downstream from a mountain range that supplies water (Box 2). In other cases the relationship between provider and consumer is indirect, for example longterm carbon storage, maintenance of biodiversity and many cultural services. Here, international agreements and treaties, such as REDD+ (Reducing Emissions from Deforestation and Forest Degradation), and voluntary markets will be necessary. REDD+ effectively represents the first global PES scheme [75], providing an incentive for improvements in forest protection and management, including restoration. Billions of US dollars have already been committed to the initiative, greatly exceeding what has previously been provided by PES schemes.

Relatively few PES schemes have focused exclusively on restoration, but some have contributed to this goal. Reforestation schemes which use commercial timber trees, such as the well-known Costa Rican PES [76], have limited ambitions in terms of ecological restoration. The Madagascan 'Mantadia' PES, by contrast, funds forest restoration to facilitate carbon sequestration and biodiversity conservation, with secondary aims that include reduced soil erosion and nutrient depletion [77]. The Chinese GTGP also has a restoration focus $[28,78]$, and farmers receive payments for 
converting sloping cropland to forest and pasture. From 1999-2006, about 9 million ha of cropland had been converted. Demonstrable impacts include increased forest cover, reduced water runoff and soil erosion, reduced river sediment loads, and supplementing rural household incomes [78]. Other benefits are anticipated in future, including habitat restoration for endangered species such as giant panda [78], although, as noted above, some negative impacts of GTGP have been reported [28].

\section{Limitations of PES for restoration}

One of the principal problems of PES schemes is their long-term sustainability, which is likely to be a key issue for restoration projects as full benefits may take many decades to accrue (Box 1). Land might be reconverted to its original use when the payments cease; in the case of the GTGP, analyses suggest that this has occurred in more than $20 \%$ of land [78]. Recent reviews of PES scheme effectiveness have emphasised some unintended consequences of introducing new markets for services, and a lack of attention to accounting for the costs of such schemes [79]. This is illustrated by efforts to restore the Everglades in Florida, USA, which have highlighted the high transaction costs associated with making payments for ecosystem services. These costs arise from the need to document the services, to negotiate and execute contracts and to deal with regulatory issues, including those relating to conservation of threatened species [80].

Furthermore, PES might skew activities towards certain services and neglect other services and biodiversity; for example where investors favour certain services over others [81]. The REDD+ mechanism has been criticized for its focus on enhancement of forest carbon stocks, as there is a possibility that other services and social issues 
could be adversely affected $[82,83]$. Evidence also suggests that there is a trade-off between protecting biodiversity and reducing carbon emissions, indicating that REDD+ funds will need to be carefully targeted to ensure that both objectives are met [84]. Potential negative social impacts include loss of livelihoods or access to lands undergoing restoration, a risk that is particularly high in areas where land tenure is insecure. Such examples highlight the need for further research not only on the use of PES to fund restoration, but on the functioning of PES markets, and their impacts on both people and biodiversity [79].

The potential negative social impacts of restoration, such as the opportunity costs associated with changes in land use, have been little explored. Restoration activities at the Sacramento River in California, USA have been much reduced in response to local opposition, principally from farmers who were concerned about the loss of agricultural production and associated tax revenues [85]. This example highlights the fact that restoration can generate costs at locations other than that at which the restoration takes place. Another issue is that the costs and benefits of restoration should be distributed equitably in relation to the benefits that are provided. In a PES scheme supporting forest restoration in Chiapas, Mexico, the poorest farmers, women and the landless were in some cases excluded from project activities [86]. This case emphasises the critical role of property rights and local institutions in shaping the distribution of benefits. Approaches needed to achieve equitability are therefore likely to vary among communities and socio-economic contexts [86]. Analysis of factors influencing distribution of the costs and benefits of restoration, and associated ecosystem services, remains an important research priority. 


\section{Conclusions and future directions}

New approaches to restoring biodiversity and ecosystem services

While recent evidence indicates that restoration can be successful in increasing both biodiversity and ecosystem services, it should not be assumed that restoring biodiversity will inevitably enhance ecosystem services, or vice versa. Biodiversity and different ecosystem services might display contrasting trajectories during restoration, leading to conflicts and trade-offs. Restoration actions focusing on a particular ecosystem service could lead to negative impacts on biodiversity or provision of other services, which will need to be considered during the planning process. Resolution of conflicts in delivery of different services and biodiversity will likely require a participatory process to land use planning. This approach would require a better understanding of how provision of ecosystem services varies at a range of scales in relation to ecosystem condition; for example, water provisioning is a complex process that can only be managed effectively at the catchment scale in relation to patterns of land use [87].

Global environmental change, including climate change, spread of invasive species and increased pollution could strongly affect our ability to restore systems. One response would be to determine how restoration might be used to increase resilience of biodiversity and ecosystem services to global change [88]. Recent progress in understanding the resilience of coupled social-ecological systems [89] provides a basis for understanding how this might be achieved in practice. Further research should identify thresholds beyond which ecological recovery might be slow or impossible, and should suggest how changes in human behaviour might be achieved to address the causes of ecological degradation. 


\section{Restoration success and future benefits}

Identification of the benefits from restoration, in terms of both biodiversity conservation and provision of ecosystem services to people, requires an understanding of restoration outcomes. As shown here, the trajectories of ecosystem services and biodiversity in a restoration can vary both in shape and rate of change. Understanding the causes of such variation represents a research priority for the future, and is a key challenge for the development of restoration as a predictive science. A further important unknown is whether trajectories for the recovery of ecosystem services coincide with those for biodiversity. This is critical not only in considering the success of a restoration project, but also in calculating its cost-effectiveness.

The use of discounting also has major implications for the valuation of benefits in the future, as the exponential function often employed short-changes the value of these services to following generations. The ethos of sustainable development requires that the future of nature and human well-being be considered, and this has led to suggestions that discounting is not appropriate in relation to ecological restoration projects [65].

These uncertainties indicate a need for realism in using restoration to reverse environmental degradation and in forecasting benefits. While it is clear that better ecological and economic information is needed, modelling approaches can help assess the uncertainties in projections and identify those factors that are most influential (e.g. [66]). 
Payments for ecosystem services and restoration goals

While the use of ecosystem service markets to support restoration has been questioned in terms of the ability of restoration to deliver specified services [90], it is also appropriate to ask whether PES can help achieve restoration goals, such as the CBD targets (see: http://www.cbd.int/decision/cop/?id=12268). PES might focus restoration activities on a limited set of services, such as carbon sequestration [8], while other services or biodiversity are neglected. This could be a particular problem when international markets are brought into play, which might override local concerns. The desired link between reversing environmental degradation and alleviating poverty might also be undermined by an excessive reliance on market forces, as poor people do not always benefit from PES [91]. As previously noted [92], in order for PES to be successful, there is a need to develop local and regional institutional frameworks which can cope with the complexity of such schemes, and which can integrate PES within existing rural development policies and programmes. For restoration to contribute both to sustainable development and the alleviation of poverty it is essential that such financial flows compensate landholders adequately for any costs of restoration, and provide an effective incentive to initiate restoration actions. Identifying how this might be achieved, based on an understanding of the potential distribution of benefits among different stakeholders and the conflicts that could arise, represents a major challenge to future restoration research and practice.

\section{Acknowledgements}

J.M.B and R.F.P were supported by CEH project NEC04166. J.M.R.B was funded by Spanish Ministry of Science and Education projects CGL2007-60533-BOS and 
CGL2010-18312, and the Madrid Government REMEDINAL project S2009AMB1783.

\section{References}

1 Butchart, S.H.M. et al. (2010) Global biodiversity: indicators of recent declines. Science 328 1164-1168

2 Secretariat of the Convention on Biological Diversity. (2010) Global Biodiversity Outlook 3. CBD, Montreal, Canada.

3 Halpern, B.S. et al. (2008) A global map of human impact on marine ecosystems. Science 319 948-952

4 Sachs, J.D. et al. (2009) Biodiversity conservation and the Millennium Development Goals. Science 325, 1502-1503

5 Ehrlich, P.R.and Pringle, R.M. (2008) Where does biodiversity go from here? A grim business-as-usual forecast and a hopeful portfolio of partial solutions. Proc. Natl. Acad. Sci. USA 105, 11579-11586

6 Day, J.W. et al. (2009) Ecology in times of scarcity. Bioscience 59, 321-331

7 Nellemann, C.and Corcoran, E., eds (2010) Dead planet, living planet - biodiversity and ecosystem restoration for sustainable development. United Nations Environment Programme, Arendal, Norway.

8 Putz, F.E.and Redford, K.H. (2009) Dangers of carbon-based conservation. Global Environ. Change 19, 400-401

9 McCauley, D.J. (2006) Selling out on nature. Nature 443, 27-28

10 Rands, M.R.W., et al. (2010) Biodiversity Conservation: Challenges Beyond 2010. Science 329, 1298-1303 
11 Society for Ecological Restoration International Science and Policy Working Group (2004) SER International Primer on Ecological Restoration. Society for Ecological Restoration International

12 Millennium Ecosystem Assessment. (2005) Ecosystems and human well-being: biodiversity synthesis. World Resources Institute

13 Engel, S. et al. (2008) Designing payments for environmental services in theory and practice: an overview of the issues. Ecol. Econ. 65, 663-674

14 Perrings, C. et al. (2010) Ecosystem services for 2020. Science 330, 323-324

15 Tallis, H. et al. (2008) An ecosystem services framework to support both practical conservation and economic development. Proc. Natl. Acad. Sci. USA 105, 94579464

16 Carpenter, S.R. et al. (2009) Science for managing ecosystem services: Beyond the Millennium Ecosystem Assessment. Proc. Natl. Acad. Sci. USA 106, 1305-1312

17 Balvanera, P. et al. (2006) Quantifying the evidence for biodiversity effects on ecosystem functioning and services. Ecol. Lett. 9, 1146-1156

18 Bullock, J.M. et al. (2007) Long-term enhancement of agricultural production by restoration of biodiversity. J. Appl. Ecol. 44, 6-12

19 Reiss, J. et al. (2009) Emerging horizons in biodiversity and ecosystem functioning research. Trends Ecol. Evol. 24, 505-514

20 Cardinale, B.J. et al. (2006) Effects of biodiversity on the functioning of trophic groups and ecosystems. Nature 443, 989-992

21 McIntyre, P.B. et al. (2007) Fish extinctions alter nutrient recycling in tropical freshwaters. Proc. Natl. Acad. Sci. USA 104, 4461-4466 
22 Nelson, E. et al. (2009) Modeling multiple ecosystem services, biodiversity conservation, commodity productionand tradeoffs at landscape scales. Front. Ecol. Environ. 7, 4-11

23 Naidoo, R. et al. (2008) Global mapping of ecosystem services and conservation priorities. Proc. Natl. Acad. Sci. USA 105, 9495-9500

24 Anderson, B.J. et al. (2009) Spatial covariance between biodiversity and other ecosystem service priorities. J. Appl. Ecol. 46, 888-896

25 Rey Benayas, J.M. et al. (2009) Enhancement of biodiversity and ecosystem services by ecological restoration: a meta-analysis. Science, 325, 1121-1124

26 Ostle, N.J. et al. (2009) UK land use and soil carbon sequestration. Land Use Policy 26, S274-S283

27 Dawson, J.J.C.and Smith, P. (2007) Carbon losses from soil and its consequences for land-use management. Sci. Total Environ. 382, 165-190

28 Cao, S.X. et al. (2009) Impact of China's Grain for Green Project on the landscape of vulnerable arid and semi-arid agricultural regions: a case study in northern Shaanxi Province J. Appl. Ecol. 46, 536-543

29 Koch, J.M. and Hobbs, R.J. (2007) Synthesis: is Alcoa successfully restoring a jarrah forest ecosystem after bauxite mining in Western Australia? Rest. Ecol., 15, S137-S144

30 Clements, W.H. et al. (2010) Quantifying restoration success and recovery in a metal-polluted stream: a 17-year assessment of physicochemical and biological responses. J. Appl. Ecol. 47, 899-910

31 Lorenz, A.W., et al. (2009) Re-meandering German lowland streams: qualitative and quantitative effects of restoration measures on hydromorphology and macroinvertebrates. Environ. Man. 44, 745-754 
32 Nehring, S.and Hesse, K.J. (2008) Invasive alien plants in marine protected areas: the Spartina anglica affair in the European Wadden Sea. Biol. Invasions 10, 937950

33 Ren, H. et al. (2009) Sonneratia apetala Buch.Ham in the mangrove ecosystems of China: An invasive species or restoration species? Ecol. Eng. 35, 1243-1248

34 Komonen, A.and Kouki, J. (2008) Do restoration fellings in protected forests increase the risk of bark beetle damages in adjacent forests? A case study from Fennoscandian boreal forest. Forest Ecol. Manag. 255, 3736-3743

35 Fulford, R.S. et al. (2010) Evaluating ecosystem response to oyster restoration and nutrient load reduction with a multispecies bioenergetics model. Ecol. Appl. 20, $915-934$

36 Aronson, J., et al. (1995) On the need to select an ecosystem of reference, however imperfect - a reply to Pickett and Parker. Restor. Ecol. 3, 1-3

37 Aronson, J., Milton, S.J. and Blignaut, J., eds. (2007) Restoring Natural Capital: Science, Businessand Practice. Island Press

38 Dodds, W.K. et al. (2008) Comparing ecosystem goods and services provided by restored and native lands. BioScience 58, 837-845

39 Jones, H.P.and Schmitz, O.J. (2009) Rapid recovery of damaged ecosystems. PLoS ONE 4 e5653. doi:10.1371/journal.pone.0005653

40 Fagan, K.C. et al. (2008) Do restored calcareous grasslands on former arable fields resemble ancient targets? The effect of time, methods and environment on outcomes. J. Appl. Ecol. 45, 1293-1303

41 Ballantine, K. and Schneider, R. (2009) Fifty-five years of soil development in restored freshwater depressional wetlands. Ecol. Appl. 19, 1467-1480 
42 Lebrija-Trejos, E. et al. (2008) Successional change and resilience of a very dry tropical deciduous forest following shifting agriculture. Biotropica 40, 422-431

43 Micheli, F. et al. (2004) Trajectories and correlates of community change in notake marine reserves. Ecol. Appl. 14, 1709-1723

44 Meyer, C.K. et al. (2008) Ecosystem recovery across a chronosequence of restored wetlands in the platte river valley. Ecosystems 11, 193-208

45 Matthews, J.W. et al. (2009) Trajectories of vegetation-based indicators used to assess wetland restoration progress. Ecol. Appl. 19, 2093-2107

46 Pywell, R.F., et al. (2011) Long-term heathland restoration on former grassland: The results of a 17-year experiment. Biol. Conserv. 144, 1602-1609

47 Jähnig, S.C. et al. (2010) A comparative analysis of restoration measures and their effects on hydromorphology and benthic invertebrates in 26 central and southern European rivers. J. Appl. Ecol. 47, 671-680

48 Klimkowska, A. et al. (2007) Wet meadow restoration in Western Europe: A quantitative assessment of the effectiveness of several techniques. Biol. Conserv. $140,318-328$

49 Seabloom, E.W. (2007) Compensation and the stability of restored grassland communities. Ecol. Appl. 17, 1876-1885

50 Schulte, D.M. et al. (2009) Unprecedented restoration of a native oyster metapopulation. Science 325, 1124-1128

51 Fagan, K.C., et al. (2010) Are ants useful indicators of restoration success in temperate grasslands? Restor. Ecol. 18, 373-379

52 Chazdon, R.L. (2008) Beyond deforestation: restoring forests and ecosystem services on degraded lands. Science 320, 1458-1460 
53 Matthews, J.W. and Spyreas, G. (2010) Convergence and divergence in plant community trajectories as a framework for monitoring wetland restoration progress. J. Appl. Ecol. 47, 1128-1136

54 Garcia-Palacios, P. et al. (2010) Dominant plant species modulate responses to hydroseeding, irrigation and fertilization during the restoration of semiarid motorway slopes. Ecol. Eng. 36, 1290-1298

55 Dunnett, N. (2011) Urban meadows: an ecological discussion. Aspects Appl. Biol. $108,11-17$

56 Jackson, S.T.and Hobbs, R.J. (2009) Ecological restoration in the light of ecological history. Science 325, 567-569

57 Aronson, J. et al. (2010) Are socioeconomic benefits of restoration adequately quantified? a meta-analysis of recent papers (2000-2008) in Restoration Ecology and 12 other scientific journals. Restor. Ecol. 18, 143-154

58 Sathirathai, S. and Barbier, E.B. (2001) Valuing mangrove conservation in Southern Thailand. Contemp. Econ. Policy 19, 109-122

59 Agraz-Hernández, C.M. et al. (2007) Restauración con manglare: Criterios y técnicas hidrológicas, de reforestación y forestación. Universidad Autónoma de Campeche, Centro EPOMEX, Comisión Federal de Electricidad, Comisión Nacional Forestal

60 Neßhöver, C. et al. (2011). Investing in ecological infrastructure. In The Economics of Ecosystems and Biodiversity: National and International Policy Making. An output of TEEB (ten Brink, P., ed.), Earthscan

61 Woodworth, P. (2006). Working for water in South Africa: saving the world on a single budget. World Policy J. 23, 31-43 
62 Kareiva, P., et al., eds (2011) Natural Capital: Theory and Practice of Mapping Ecosystem Services. Oxford University Press

63 Faber S. et al. 2006. Linking ecology and economics for ecosystem management: a services-based approach with illustrations from LTER Sites. Biosience 56, 121-133

64 Currie B. et al. (2009) Cost-benefit analysis of alien vegetation clearing for water yield and tourism in a mountain catchment in the Western Cape of South Africa. Ecol. Econ. 68, 2574-2579

65 Rees W.E. et al. (2007) Valuing natural capital and the costs and benefits of restoration. In Restoring Natural Capital. Science, Businessand Practice (Aronson, J., Milton, S.J. and Blignaut, J.N. eds), pp 227-236, Island Press

66 Birch, J. et al. (2010). Cost-effectiveness of dryland forest restoration evaluated by spatial analysis of ecosystem services. Proc. Natl. Acad. Sci. USA 107(50), $21925-$ 21930.

67 Blignaut, J.N. et al. (2010). Restoring and managing natural capital towards fostering economic development: evidence from the Drakensberg, South Africa. Ecol. Econ. 69, 1313-1323

68 Goldstein, J.H. et al. (2008) Using return-on-investment to guide restoration: a case study from Hawaii. Conserv. Letters 1, 236-243

69 Blignaut, J.N. and Moolman, C.E. (2006) Quantifying the potential of restored natural capital to alleviate poverty and help conserve nature: A case study from South Africa. J. Nat. Cons. 14, 237-248

70 Bekessy, S.A., et al. (2010) The biodiversity bank cannot be a lending bank. Conserv. Lett. 3, 151-158 
71 Jack, B.K. et al. (2008) Designing Payments for Ecosystem Services: lessons from previous experience with incentive- based mechanisms. Proc. Natl. Acad. Sci. USA $105,9465-9470$

72 Farley, J. et al. (2010) Global mechanisms for sustaining and enhancing PES schemes. Ecol. Econ. 69, 2075-2084

73 Wunder, S. et al. (2008) Taking stock: a comparative analysis of payments for environmental services programs in developed and developing countries. Ecol. Econ. $65,834-852$

74 de Groot, R. et al. (2010) Integrating the ecological and economic dimensions in biodiversity and ecosystem service valuation. In: The Economics of Ecosystems and Biodiversity: Ecological and Economic Foundations. An output of TEEB. (Kumar P. ed), Earthscan

75 UNEP (2011) REDDy Set Go. A briefing for financial institutions. UNEP Finance Initiative, UNEP, Geneva.

76 Pagiola, S. (2008) Payments for environmental services in Costa Rica. Ecol. Econ. $65,712-724$

77 Wendland, K.J., et al. (2010) Targeting and implementing payments for ecosystem services: opportunities for bundling biodiversity conservation with carbon and water services in Madagascar. Ecol. Econ. 69, 2093-2107

78 Chen X. et al.(2009) Factors affecting land reconversion plans following a payment for ecosystem service program. Biol. Conserv. 142, 1740-1747

79 Brauman, K.A. et al. 2007. The nature and value of ecosystem services: an overview highlighting hydrologic services. Annu. Rev. Environ. Resour. 32, 67-98 
80 Bohlen, P. J. Lynch, S., Shabman, L., Clark, M., Shukla, S. and Swain, H. (2009) Paying for environmental services from agricultural lands: an example from the Northern Everglades. Front. Ecol. Environ. 7, 46-55

81 Koellner, T., et al. (2010) Why and how much are firms willing to invest in ecosystem services from tropical forests? A comparison of international and Costa Rican firms. Ecol. Econ. 69, 2127-2139

82 Stickler, C.M. et al. (2009) The potential ecological costs and cobenefits of REDD: a critical review and case study from the Amazon region. Global Change Biol. 15, 2803-2824

83 Miles, L., and Kapos, V. (2008) Reducing greenhouse gas emissions from deforestation and forest degradation: Global land-use implications. Science 320, $1454-1455$

84 Venter, O., et al. (2009) Harnessing carbon payments to protect biodiversity. Science 326, 1368-1368

85 Buckley, M.C. and Crone, E.E. (2008) Negative off-site impacts of ecological restoration: understanding and addressing the conflict. Conserv. Biol. 22, 11181124

86 Corbera, E. et al. (2007) The equity and legitimacy of markets for ecosystem services. Development and Change 38, 587-613

87 Le Maitre, D.C., et al. (2007) Linking ecosystem services and water resources: landscape-scale hydrology of the Little Karoo. Front. Ecol. Environ. 5, 261-270

88 Montoya, J.M.and Raffaelli, D. (2010) Climate change, biotic interactions and ecosystem services. Phil. Trans. Roy. Soc. B. 365, 2013-2018

89 Liu, J.G., et al. (2007) Complexity of coupled human and natural systems. Science $317,1513-1516$ 
90 Palmer, M.A.and Filoso, S. (2009) Restoration of ecosystem services for environmental markets. Science 325, 575-576

91 Wunder, S. (2008) Payments for environmental services and the poor: concepts and preliminary evidence. Environ. Devel. Econ. 13, 279-297

92 Muradian, R., et al. (2010) Reconciling theory and practice: An alternative conceptual framework for understanding payments for environmental services. Ecol. Econ. 69, 1202-1208 


\section{Figure legends}

Fig. 1. The indirect links between biodiversity and ecosystem services, as illustrated by contrasting outcomes of restoration activities on aspects of biodiversity and ecosystem services.

A species-poor agricultural grassland can be converted to a species-rich hay meadow with the aim of enhancing native species diversity. Compared with the original ecosystem, this causes a small increase in carbon sequestration [26], but has no effect on water use and the lack of fertilisers leads to a decline in forage production [18]. A high species number counters the drop in productivity to some degree [18], as indicated by the arrow between the two. Planting of non-native trees with the aim of greatly increasing carbon sequestration also allows production of wood [27], but native species richness declines and an increase in water use by the vegetation reduces water availability [28]. Other services and aspects of biodiversity will be affected, but these are not illustrated here for clarity. Impacts: ++ strongly positive,+ positive, 0 no change, - negative. 


\section{Glossary}

Restoration. The process of assisting the recovery of an ecosystem that has been degraded; damaged or destroyed [11].

Rehabilitation. The reparation of ecosystem processes and services, whereas restoration includes the reestablishment of biotic integrity [11].

Biodiversity. Biological diversity at all scales: the variety of ecosystems in a landscape; the number and relative abundance of species in an ecosystem; and genetic diversity within and between populations (adapted from [12])

Ecosystem services. The benefits people obtain from ecosystems [12]. There are many definitions; but a unifying feature is that services are defined as resulting from ecosystem processes or functions that provide benefits and value to humans.

Environmental degradation. The simplification or disruption of ecosystems caused by severe; unprecedented and/or prolonged anthropogenic disturbances.

Millennium Development Goals (MDG). Eight goals to meet the needs of the world's poorest people by the target date of 2015 and agreed to by all the world's countries; ranging from halving extreme poverty to providing universal primary education (see: http://www.un.org/millenniumgoals/).

Payment for ecosystem services (PES): a transaction whereby a defined ecosystem service is being bought by a buyer(s) from a provider(s); if ecosystem service provision is secured [13]

Direct use value of an ecosystem: the value of directly accessed services; usually provisioning or cultural. These are distinguished from services that have indirect use (notably regulating and supporting), and non-use values, (e.g. the value people place on nature for future use (option values) or for ethical reasons (bequest and existence values).

Return-on-investment (ROI): a suite of measures used to evaluate the efficiency of any investment or to compare the efficiency of a number of investments. ROI is calculated as a percentage or a ratio of the benefit (return) of an investment divided by its cost. 
Box. 1. Restoration trajectories and the rate of recovery

Trajectories of biodiversity and ecosystem services towards the desired reference exhibit great variation in the pattern and rate of change. Analysis of actual restoration trajectories of individual measures indicates they can be asymptotic $(a, b)$, linear (c), unimodal (d), or stochastic (e) over time [40-46]. Asymptotic and linear trajectories might approach the reference within a reasonable time period (a, c), or might indicate very slow progress (b). Unimodal and stochastic trajectories are unlikely ever to reach the reference state. Thus, the restored system might not

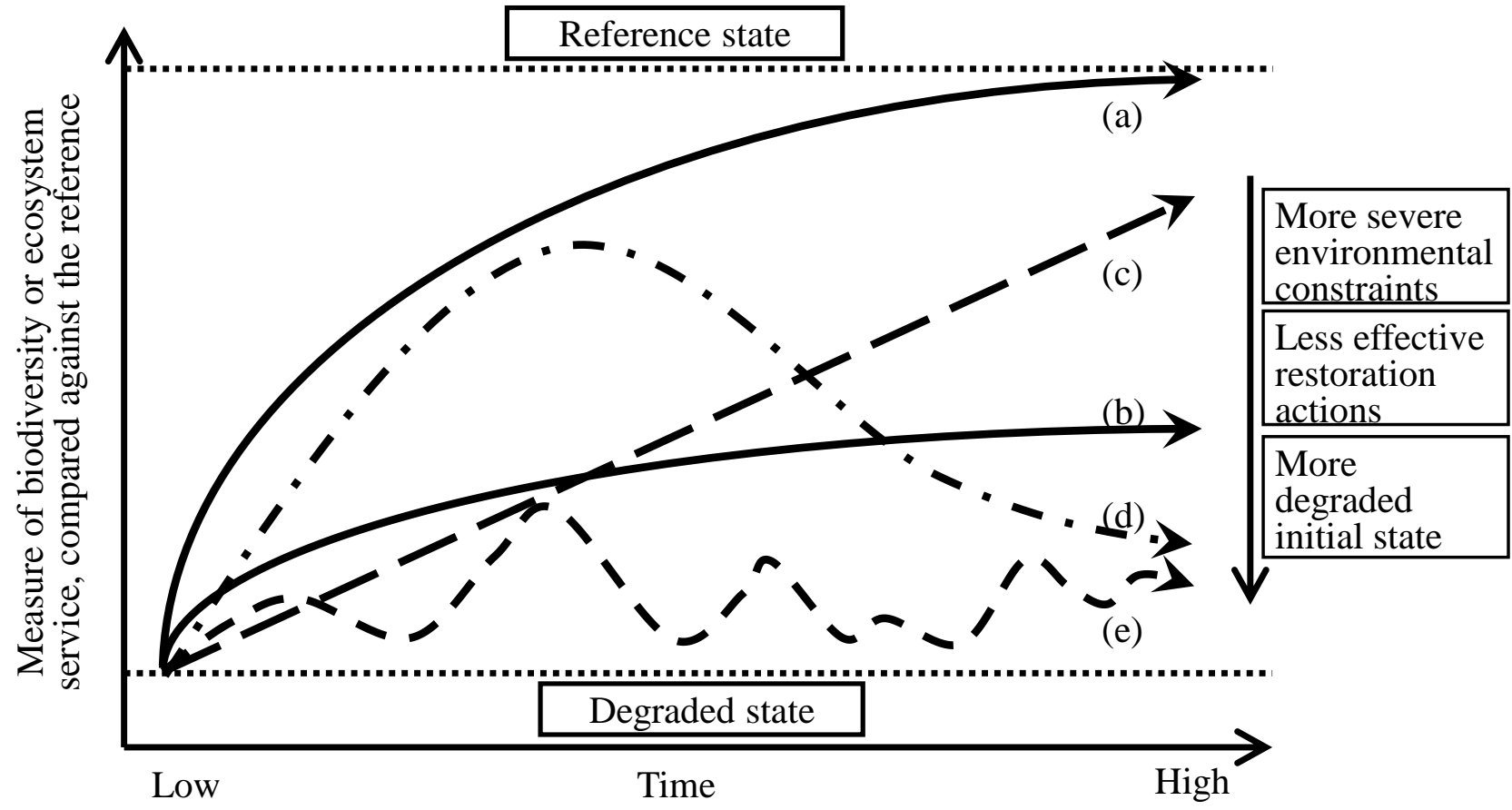
attain the reference within in an appreciable time period for some or all measures. Different measures of biodiversity and services during a single restoration can show a wide range of trajectories. In particular the rate of approach to the reference can vary strongly $[42,44,45]$; in some cases, the restored trajectory can even exceed the reference [25]. The rate of approach of the trajectory to the reference state is likely to be lower: in less productive ecosystems [25,38,47], if the initial state is more degraded [48], if certain environmental factors constrain recovery (e.g. inappropriate $\mathrm{pH}$ ) [41,49], or if less effective restoration methods are used [46$48,50]$. An analysis of reported recovery times for a range of ecosystems suggested that the pre-perturbation states of biodiversity and ecosystem function measures could be reached in a very few decades or less [39], although many of the ecosystems considered were relatively un-degraded at the outset. Other studies have suggested that recovery takes place over longer periods of time. For example, limited overlap in both plant and ant communities was found between restored and ancient calcareous grasslands even after 60 years [40,51]. Soil properties related to water quality in restored wetlands were $<50 \%$ of reference values after 55 years [41]. Restoration of forest structure and plant species takes at least 30-40 years and usually many more decades [42,52]. Finally, notake marine reserves can lead to rapid recovery of fish biomass, but it can take decades for target trophic structures to be achieved [43]. 
Box. 2. Case studies of the costs and benefits of restoration

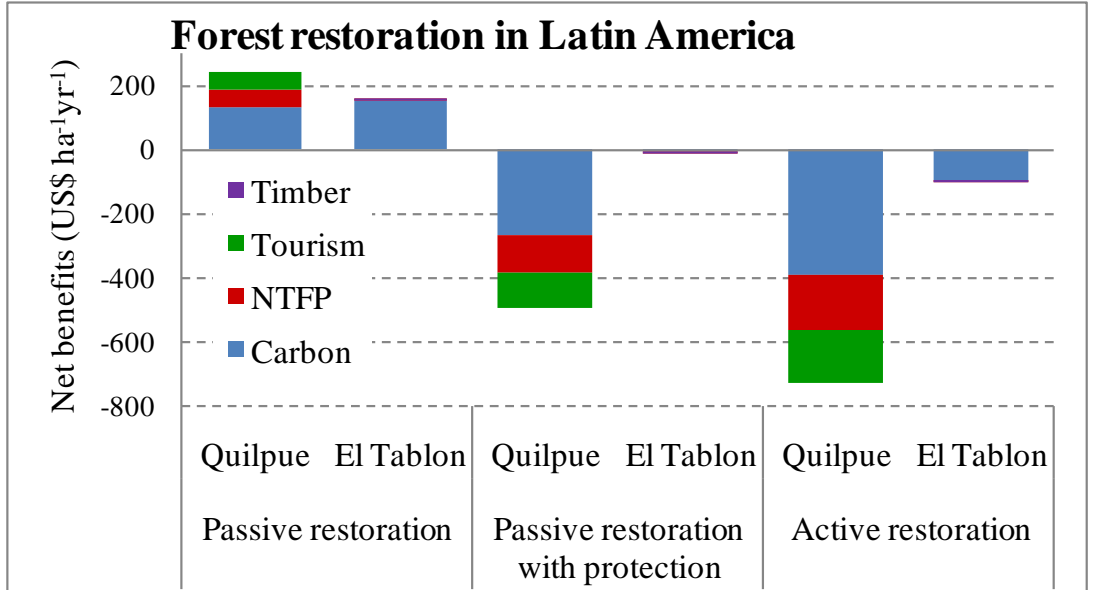

The cost-effectiveness of three forest restoration approaches in two Latin American dryland landscapes [66]: 'passive' (opportunity costs of livestock production); 'passive with protection' (added costs of fencing and

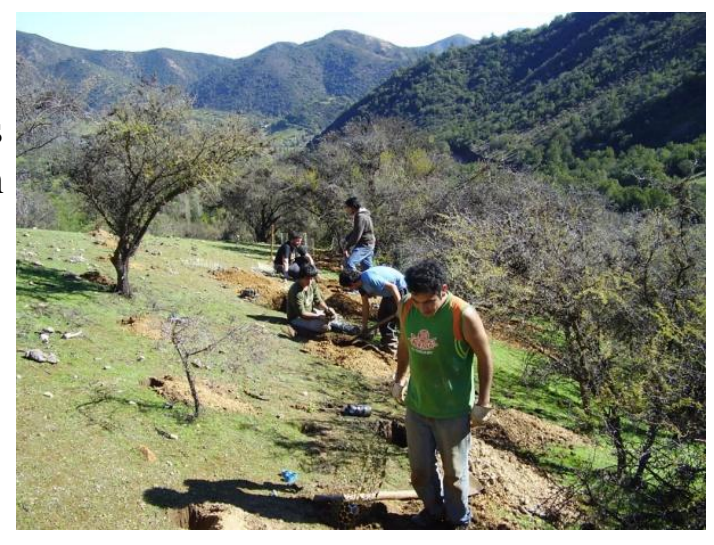

fire suppression); and 'active' (added costs of planting). The net value of four ecosystem service benefits was estimated for each scenario. Passive restoration was cost-effective for all landscapes based on these services; whereas the benefits from active restoration were outweighed by the relatively high costs involved. There was substantial variation between landscapes; in terms of current natural capital and marginal change values; demonstrating that service values are context specific. The results of this analysis were highly sensitive to the market value of carbon; but relatively insensitive to variation in discount rates.

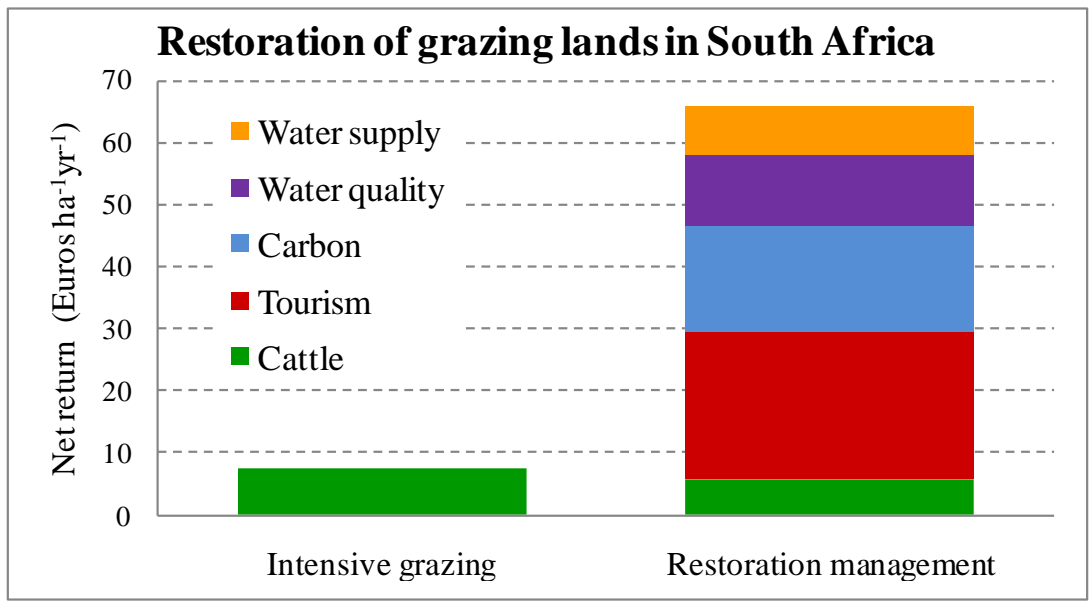

The Maloti-

Drakensberg mountain ranges supply much of S. Africa's water through rivers and inter-basin transfers. The mountain's grassland cover is essential for maintaining a regular flow of clean water;

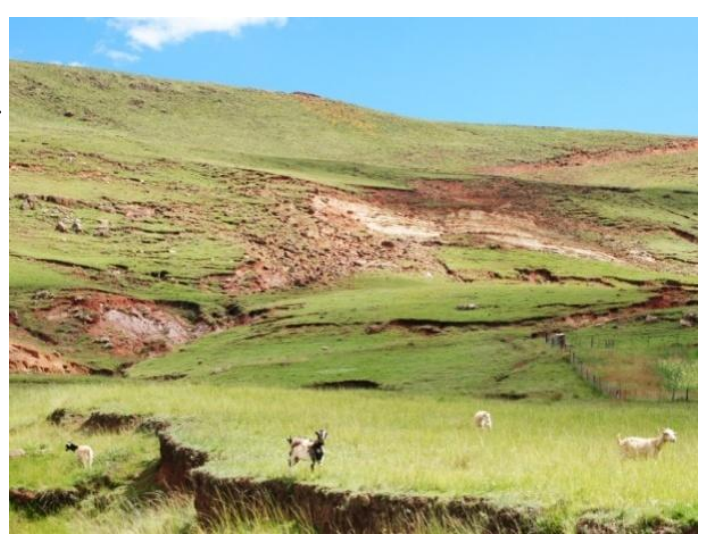
but it has been transformed through various unsustainable land uses. To address the question of how to value ecosystem services and finance payments for them; an integrated hydrologyecology-economic model was developed based on the multi-user potential for managing and restoring the natural capital of Ukombe at farmstead and watershed scales [67]. Compared against current intensive management; restoration actions provide potential returns in terms of a number of services. Furthermore. the economic return on the water flow far exceeds that of conventional water development programs. 
Fig. 1
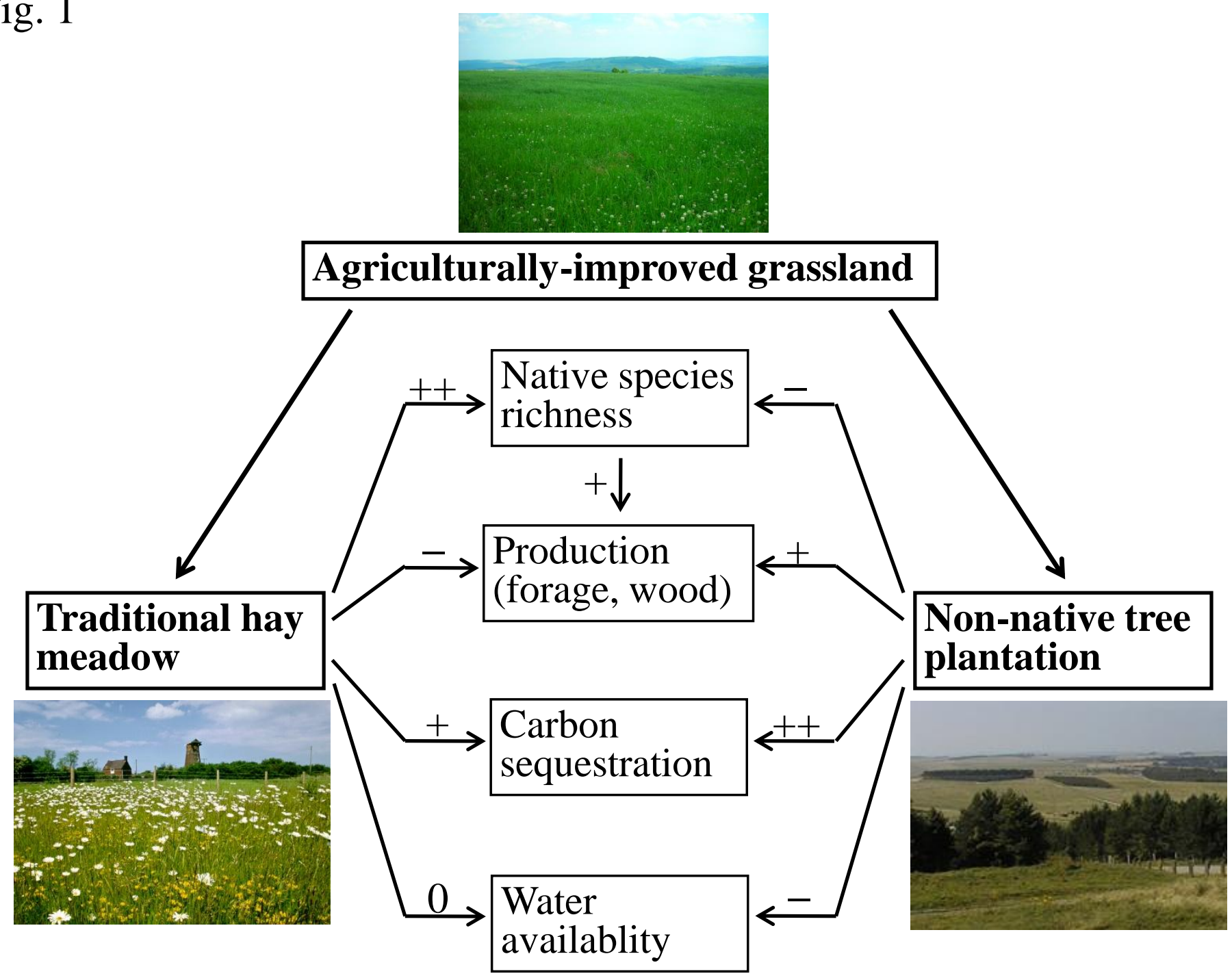